\title{
Sweet Wormwood and Tortoise Shell Decoction (Thanh Hao Miet Giap Thang) Induces DNA Damage, S-Phase Arrest, and Apoptosis in MCF-7 Cells via ATR-CHK1 Signaling Pathway
}

\author{
Hoang Tam Nguyen Thai $\mathbb{D}^{D}$, Thuy Vy Nguyen ${ }^{\mathbb{D}}$, and Thuy Duong Ho Huynh \\ Department of Genetics, Faculty of Biology and Biotechnology, University of Science, \\ VNUHCM, 227 Nguyen Van Cu Street, District 5, Ho Chi Minh City, Vietnam \\ Correspondence should be addressed to Thuy Duong Ho Huynh; hhtduong@hcmus.edu.vn
}

Received 6 April 2021; Revised 28 November 2021; Accepted 30 November 2021; Published 5 March 2022

Academic Editor: Jun Yan Tao

Copyright (c) 2022 Hoang Tam Nguyen Thai et al. This is an open access article distributed under the Creative Commons Attribution License, which permits unrestricted use, distribution, and reproduction in any medium, provided the original work is properly cited.

\begin{abstract}
Introduction. Sweet wormwood and tortoise shell decoction, Thanh Hao Miet Giap Thang (THMGT) in Vietnamese, a traditional formula composed of five ingredients, is used in complementary care in Vietnam for patients who underwent conventional cancer treatment. To expand the clinical use and explore novel functions of THMGT, this study was conducted to investigate the effect of THMGT in terms of antiproliferative activity and selective cytotoxicity toward human breast cancer cells MCF-7. Methods. Cytotoxicity of THMGT against human breast cancer cells MCF-7 and primary fibroblasts from a heathy donor were studied using sulforhodamine B (SRB) assay. Flow cytometry analysis, immunofluorescence, and western blotting were also performed to elucidate underlying mechanisms of THMGT action. Results. The SRB assay on treated MCF-7 cells and primary fibroblasts from a heathy donor indicated selective cytotoxicity of THMGT with a selective index of 3.92. Annexin V/PI staining and flow cytometric analysis on stained MCF-7 cells showed that the THMGT-treated cells were arrested at the $S$ phase and subsequently underwent apoptosis. Western blot analysis showed an upregulation of $\gamma-\mathrm{H} 2 \mathrm{AX}$, increased protein levels of phosphorylated CHK1, TP53, and phosphorylated TP53 in a time-dependent manner, and a downregulated expression of ATR and MDM2. Conclusion. These results suggested DNA damaging effect and ATR-CHK1-mediated cell cycle arrest of THMGT on MCF-7 cells resulting in apoptosis induction.
\end{abstract}

\section{Introduction}

In countries where traditional medicine is fully integrated in the national healthcare system, as in the case of Vietnam, traditional medical practices, especially herbal drug prescription, could be used as a complementary therapy provided jointly with conventional treatment or as a supportive care in cancer treatment [1-3].

The sweet wormwood and tortoise shell decoction (Qing Hao Bie Jia Tang in Chinese, Thanh Hao Miet Giap Thang (THMGT) in Vietnamese) is a traditional Chinese medicine (TCM) formula, traditionally used to treat late-stage chronic fever diseases. In Vietnam, THMGT was used as a complementary and supportive care for cancer patients. The formula includes five ingredients: Herba Artemisiae annuae,
Carapax Trionycis, Rhizoma Anemarrhenae, Moutan Cortex, and Radix Rehmanniae. Artemisia species (A. annua and $A$. apiacea) are well known for their content of artemisinin that was initially prescribed for antimalarial properties [4]. More therapeutic and preventive effects such as anti-inflammatory, antiangiogenesis, anticancer, and antioxidant were successively attributed to extracts and compounds from these plants [5-7]. Synergistic effects of different active compounds of the herb such as artemisinin, flavonoids, and polyphenols increase the overall biological activities [7]. Carapax Trionycis, the tortoise shell, was obtained from Tryonix sinensis Wiegmann. The substance alone, or combined into multi-ingredient formulae, was used for the treatment of endometriosis; it inhibits the proliferation and induces apoptosis in hepatic stellate cells 
[8-10]. Moutan Cortex, originated from Paeonia suffruticosa, was largely used in TCM for the treatment of gynecological disorders [11]. Its extracts have anti-inflammatory, antitumor, antioxidant, and antiplatelet aggregation activities and inhibit migration and metastasis of cancer cells [12-16]. Alone or combined with other herbs, Moutan Cortex has potential as antidiabetic $[17,18]$ and hepatoprotective agents [19]. Radix Rehmanniae, dried rhizome from Rehmannia glutinosa, has anti-inflammatory, antioxidant, antiglycation, and antidiabetic properties [20-24]. Rhizoma Anemarrhenae, the dried rhizome of Anemarrhena asphodeloides, has varied biological activities, including antiinflammatory, anticoagulation, analgesic, antidiabetic, antiallergic, and antitumor [25-30]. Timosaponin AIII, present in aqueous extracts of $A$. asphodeloides, induces cell death by apoptosis [31] and autophagy and has selective cytotoxicity against cancer cells $[32,33]$. However, to our best knowledge, the anticancer activity of THMGT has not been elucidated. This study aims to investigate the selective cytotoxicity of THMGT on human breast cancer cells MCF7 and underlying mechanisms causing tumor cell death.

\section{Materials and Methods}

2.1. Preparation of THMGT Decoction. THMGT was composed of five ingredients in the following dosage: Herba Artemisiae annuae L (12 g), Carapax Trionycis (Tryonix sinensis) (12 g), Rhizoma Anemarrhenae (Anemarrhena asphodeloides) (20 g), Radix Rehmanniae (Rehmannia glutinosa Libosch) (16g), and Moutan Cortex (Paeonia suffruticosa) (12 g). Carapax Trionycis was listed in Vietnamese pharmacopeia released by the Ministry of Health as Materia medica allowed for use in traditional remedies. The five crude ingredients were obtained from Tue Lan Traditional Medicine and Medical Clinic (HCMC, Vietnam) in January 2016 and identified by Dr. Duc Nghia Nguyen (Tue Lan Traditional Medicine and Medical Clinic). A voucher specimen was deposited at the Department of Genetics, University of Science (HCMC, Vietnam). A total amount of $720 \mathrm{~g}$ of all ingredients was quickly washed 2 times with distilled water and soaked in $7.2 \mathrm{~L}$ water for $30 \mathrm{~min}$ and gently boiled for $3 \mathrm{~h}$ to collect the first decoction. Soaking and boiling of ingredients were repeated to obtain the second decoction. The two decoctions were mixed and steamed to reduce to a volume of $720 \mathrm{ml}$ and finally lyophilized to obtain dried powder with amount of $172.8 \pm 10.6 \mathrm{~g}$ (yield: $24.1 \pm 1.5 \%$ ). The dried powder was dissolved in distilled water to get a final concentration of $100 \mathrm{mg} / \mathrm{ml}$, and the solution was passed through $0.22-\mu \mathrm{m}$ filter for sterilization.

2.2. Chemical Fingerprint Analysis by High-Performance Liquid Chromatography (HPLC). The dried powder of THMGT was dissolved with HPLC grade methanol (Merck) to a concentration of $10 \mathrm{mg} / \mathrm{ml}$ and filtered through a $0.45 \mu \mathrm{m}$ HPLC syringe filter. Analysis of extracts was carried out using a LC-20AD Shimadzu HPLC system with a PDAM20A detector. Separation was performed on a C-18 column $(150 \mathrm{~mm} \times 4.6 \mathrm{~mm}, 5 \mu \mathrm{m}$; Supelcosil TM, LC-18). The mobile phase consisted of two solvents, double-distilled water (A) and acetonitrile (B). The gradient elution program was set as follows: $0-11 \mathrm{~min}, 80: 20$ (A : B); 11-25 min, $65: 35$ (A : B); 25-40 min, $55: 45$ (A : B); 40-65 min, $5: 95$ (A : B); 65-70 $\mathrm{min}, 80: 20(\mathrm{~A}: \mathrm{B})$; and $66-70 \mathrm{~min}$. The injection volume was $20 \mu \mathrm{l}$ and the flow rate was maintained at $1.0 \mathrm{ml} /$ min. The column temperature was set at $25^{\circ} \mathrm{C}$ and the wavelength used for detection was $230 \mathrm{~nm}$.

2.3. Cell Line and Primary Fibroblast Culture. MCF-7 cells (HTB-22) were obtained from the American Type Culture Collection (Manassas, Rockville). Cells were grown as monolayer cultures at $37^{\circ} \mathrm{C}$ and $5 \% \mathrm{CO}_{2}$, in Eagle's minimal essential medium (E'MEM) supplemented with $10 \%(\mathrm{v} / \mathrm{v})$ FBS (Sigma), $2 \mathrm{mM}$ L-glutamine (Sigma), $20 \mathrm{mM}$ HEPES (Sigma), $0.025 \mu \mathrm{g} / \mathrm{ml}$ amphotericin B (Sigma), $100 \mathrm{IU} / \mathrm{ml}$ penicillin G (Sigma), and $100 \mu \mathrm{g} / \mathrm{ml}$ streptomycin (Sigma). Primary fibroblasts were isolated and identified as previously described [34]. The donor donating tissues gave written informed consent, and this study was approved by the Ethical Committee for Biomedical Research of the Vietnam National University, Ho Chi Minh City (Ref. 1387 QĐĐHQG). Cells were cultured in D’MEM/F12 supplemented with $10 \%$ (v/v) FBS, $20 \mathrm{mM}$ HEPES, $0.025 \mu \mathrm{g} / \mathrm{ml}$ amphotericin $\mathrm{B}, 100 \mathrm{IU} / \mathrm{ml}$ penicillin $\mathrm{G}$, and $100 \mu \mathrm{g} / \mathrm{ml}$ streptomycin at $37^{\circ} \mathrm{C}, 5 \% \mathrm{CO}_{2}$.

2.4. SRB Assay. The assay was performed as previously described [34]. Cells were seeded in 96-well plates (SPL Life Sciences) at a density of $1 \times 10^{4}$ cells/well. After $24 \mathrm{~h}$ of culture, cells were treated with THMGT at different concentrations for $48 \mathrm{~h}$. Treated cells were fixed with 50\% (w/v) cold trichloroacetic acid (Merck) for 1-3h, washed and stained with $0.2 \%(\mathrm{w} / \mathrm{v})$ sulforhodamine B (SRB) (Sigma) for $20 \mathrm{~min}$. A protein-bound dye was dissolved in $10 \mathrm{mM}$ Trisbase solution (Promega) after five washes with 1\% acetic acid to remove the unbound dye. Optical density values were determined at wavelengths of $492 \mathrm{~nm}$ and $620 \mathrm{~nm}$ using a 96-well microtiter plate reader (Synergy HT, Biotek Instruments). The percentage of growth inhibition (I\%) was calculated according to the formula: $\mathrm{I} \%=(1-(\mathrm{ODt} / \mathrm{ODc}) \times$ $100) \%$, where ODt and ODc are the optical density value of test and control samples, respectively. Camptothecin (CPT) was used as a positive control.

2.5. MTT Assay. The assay was performed as previously described [35]. Cells were seeded in 96-well plates (SPL Life Sciences) at a density of $1 \times 10^{4}$ cells/well. After $24 \mathrm{~h}$ of culture, cells were treated with THMGT at a concentration of $3 \mathrm{mg} / \mathrm{ml}$ for 3, 6, and $9 \mathrm{~h}$. After THMGT treatment, $100 \mu \mathrm{l}$ of MTT solution $(0.5 \mathrm{mg} / \mathrm{ml})$ was added to each well, and the plates were incubated for $4 \mathrm{~h}$ at $37^{\circ} \mathrm{C}$, and then the media were removed. After dissolving the formazan crystals in $200 \mu \mathrm{l}$ of DMSO, the absorbance of each plate was measured at $570 \mathrm{~nm}$ and $620 \mathrm{~nm}$ using a 96-well microtiter plate reader (Synergy HT, Biotek Instruments). The percentage of proliferative inhibition (I\%) 
was calculated according to the formula: I\% $=(1-[\mathrm{ODt} /$ ODc] $\times 100) \%$, where ODt and ODc are the optical density value of test and control samples, respectively.

2.6. Cell Cycle Analysis. MCF-7 cells were cultured for $24 \mathrm{~h}$ at a density of $2 \times 10^{6}$ cells per $10 \mathrm{~cm}$ dish (SPL Life Sciences). Cells were subsequently treated with $3 \mathrm{mg} / \mathrm{ml}$ THMGT for 3 , 6, and $9 \mathrm{~h}$. Cells were then collected in Trypsin/EDTA, fixed in cold $70 \%(\mathrm{v} / \mathrm{v})$ ethanol, and stored at $-20^{\circ} \mathrm{C}$ for at least $24 \mathrm{~h}$. After washing two times with PBS, cells were incubated with $0.2 \mathrm{mg} / \mathrm{ml} \mathrm{RNase}$ for $30 \mathrm{~min}$ at $37^{\circ} \mathrm{C}$ and subsequently stained with $10 \mu \mathrm{g} / \mathrm{ml}$ propidium iodide staining buffer for $15 \mathrm{~min}$ at room temperature. DNA content was analyzed by BD Accuri C6 Plus Flow cytometry (BD Biosciences).

2.7. Annexin V/PI Staining for Apoptosis Detection. MCF-7 cells were cultured for $24 \mathrm{~h}$ at a density of $2 \times 10^{6}$ cells per $10 \mathrm{~cm}$ dish (SPL Life Sciences). Cultured cells were exposed to THMGT at concentration of $3 \mathrm{mg} / \mathrm{ml}$ for 3,6 , and $9 \mathrm{~h}$. Annexin V/PI staining was performed according to FITC Annexin V Apoptosis Detection Kit II (BD) protocol. Stained cells were analyzed by BD Accuri C6 Plus Flow cytometry (BD Biosciences). Results were determined as follows: viable cells expressed (-) Annexin V/(-) PI, necrotic cells were (-) Annexin V/(+) PI, early apoptotic cells were (+) Annexin V/ $(-)$ PI, and late apoptotic cells were (+) Annexin V/(+) PI.

2.8. Western Blotting. MCF-7 cells were lyzed by a RIPA buffer (Thermo Scientific Pierce, USA) containing protease inhibitor cocktail (Complete Protease Inhibitor Cocktail Tablets, Roche Diagnostics GmbH, USA). Lysates were quantitated by the BCA Protein Assay kit (Thermo Scientific Pierce, USA). An amount of $30 \mu \mathrm{g}$ of total protein samples was analyzed by SDS-PAGE and transferred onto nitrocellulose membranes. After blocking step with a blocking buffer, membranes were incubated overnight at $4^{\circ} \mathrm{C}$ with primary antibodies. Membranes were subsequently rinsed 5 times with washing buffer $(0.1 \%(\mathrm{v} / \mathrm{v})$ Tween in $1 \mathrm{X}$ PBS or $0.1 \%(\mathrm{v} / \mathrm{v})$ Tween in $1 \mathrm{X}$ TBS) and incubated with horseradish peroxidase-conjugated secondary antibody for $1 \mathrm{~h}$ at room temperature. Finally, membranes were washed 5 times with washing buffer. Protein signals were visualized by SuperSignal West Pico Chemiluminescent Substrate (Thermo Scientific Pierce, USA) and scanned by ImageQuant LAS 500 (GE Healthcare Biosciences, UK). Antibodies used for western blot in this study are listed in Supplementary Table S1. $\beta$-Actin was used for normalization, and the protein expression was evaluated relative to the nontreated cells at each time point.

2.9. Immunofluorescence Microscopy. Cells were seeded at a density of $1.5 \times 10^{5}$ cells per $22 \times 22 \mathrm{~mm}$ glass coverslip (Duran) and cultured for $24 \mathrm{~h}$ at $37^{\circ} \mathrm{C}$ and $5 \% \mathrm{CO}_{2}$. Cells were subsequently exposed to $3 \mathrm{mg} / \mathrm{ml}$ THMGT for $3 \mathrm{~h}$. Coverslips were washed with 1 X PBS (-), fixed with $4 \%$ (w/v) paraformaldehyde in 10 mins, incubated in TBS 1 X $0.3 \%(\mathrm{v} /$ v) Triton X-100 for $20 \mathrm{~min}$, blocked in $0.2 \%(\mathrm{w} / \mathrm{v}) \mathrm{BSA}$ in
$60 \mathrm{~min}$ at room temperature with shaking, and incubated with $\gamma$-H2AX antibody (sc-517348, 1:200 dilution) overnight at $4^{\circ} \mathrm{C}$ in a humid chamber. After being washed with TBS $1 X 0.1 \%(\mathrm{v} / \mathrm{v})$ Tween-20 and incubated with Alexa 488 anti-mouse antibody for $60 \mathrm{~min}$ at room temperature in a humid chamber, coverslips were washed with TBS $1 \mathrm{X} 0.1 \%$ (v/v) Tween-20 and incubated with $10 \mu \mathrm{l}$ Hoechst $(1 \mu \mathrm{g} / \mathrm{ml})$ for $10 \mathrm{~min}$ at room temperature. Finally, coverslips were mounted and observed on a fluorescence microscope. For each condition, at least 100 cells from three independent experiments were scored, and cells with more than four foci per nucleus were graded as positive.

2.10. Statistical Analysis. Data were represented as mean$\mathrm{s} \pm$ standard deviation (SD). Statistical analyses were performed using a two-tailed Student's $t$ test. Results were considered statistically significant at $p$ value $<0.05$.

\section{Results}

3.1. Chemical Fingerprint of the THMGT Formula. The HPLC fingerprint chromatogram of THMGT is shown in Figure 1. Paeonol and artemisinin were well identified in THMGT by comparing both retention times and UV spectra. Our results also showed that HPLC chromatograms of THMGT decoctions have similar patterns, suggesting reproducibility in the preparation technology and the quality of the medicinal materials (Figure 1(c)).

3.2. THMGT Exerted Selective Cytotoxicity in MCF-7 Cells. An ideal anticancer compound is one that has selective cytotoxicity toward tumor cells with no or less toxicity against normal cells. Selective cytotoxicity was measured through the selective index (SI). The more the SI value of a compound is great, the more it displays selective cytotoxicity. An SI value less than 2 indicates nonselectivity. We assessed the selective cytotoxicity of THMGT through calculation of its SI. The SI value was determined as the ratio between $\mathrm{IC}_{50}$ values of the formula for human primary fibroblasts and for human breast cancer cells MCF-7. The fibroblasts and MCF-7 cells were treated with the same serial dilution of THMGT and subjected to SRB assay to determine $\mathrm{IC}_{50}$ values (Figure 2). IC 50 values of THMGT for MCF-7 cells and fibroblasts were $0.79 \pm 0.08$ and $3.06 \pm 0.11 \mathrm{mg} / \mathrm{ml}$, respectively, giving a SI of $3.92 \pm 0.43$. As a positive control, $\mathrm{IC}_{50}$ values of CPT for MCF-7 cells and fibroblasts were $0.10 \pm 0.01$ and $0.54 \pm 0.17 \mu \mathrm{g} / \mathrm{ml}$, respectively, giving a SI of $5.13 \pm 1.14$.

3.3. THMGT Executed Its Selective Cytotoxic Effects through Induction of DSBs in MCF-7 Cells. Several anticancer drugs selectively kill cancer cells by inducing DNA damage; the genomic instability and DNA repair defects of cancer cells make them more vulnerable than normal cells to the cytotoxicity of DNA-damaging agents [36]. Among DNA lesions, DSB is considered to be the most severe form of DNA damage. To elucidate the possible mechanisms of 


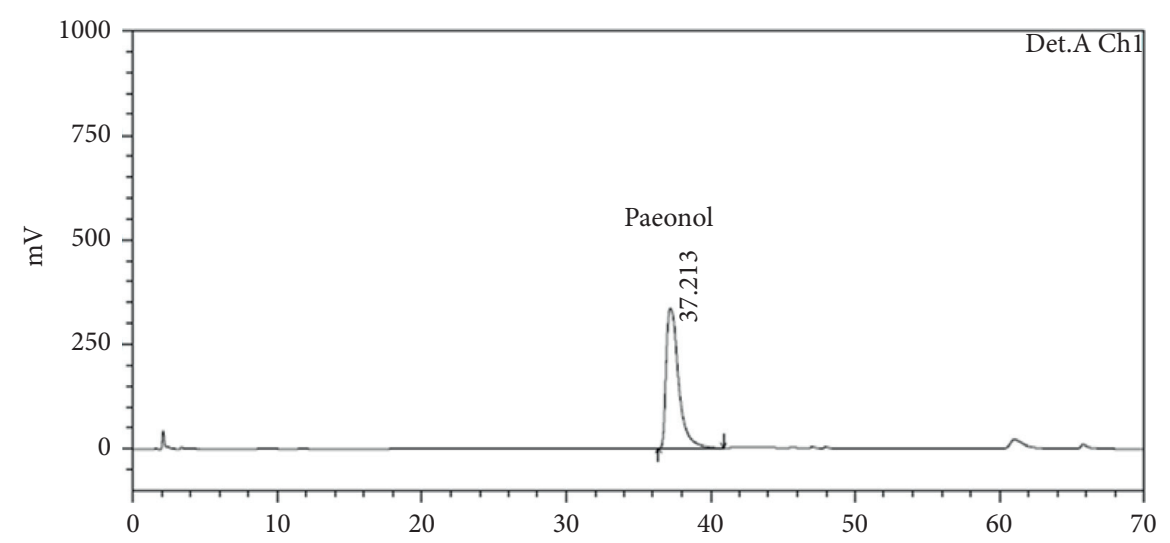

(a)

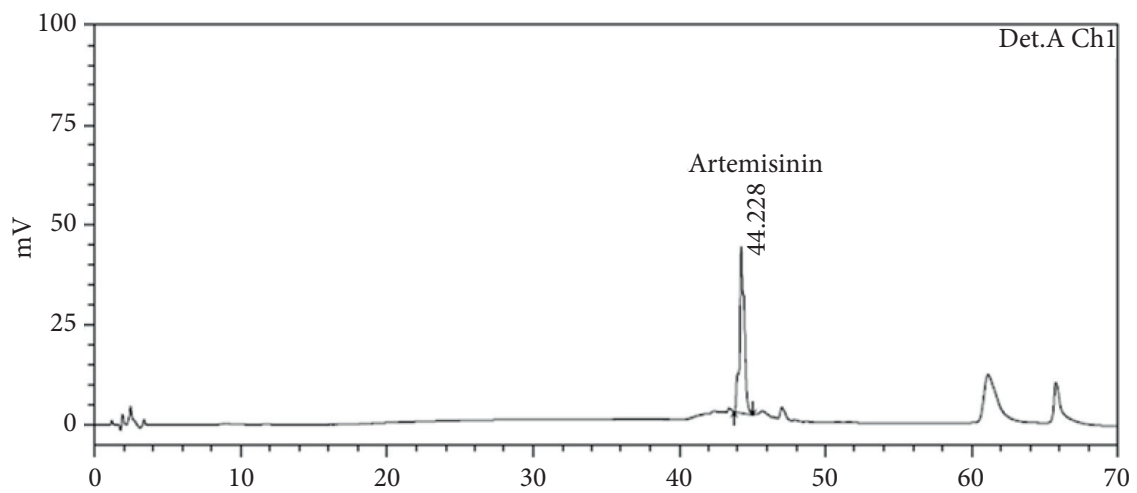

(b)

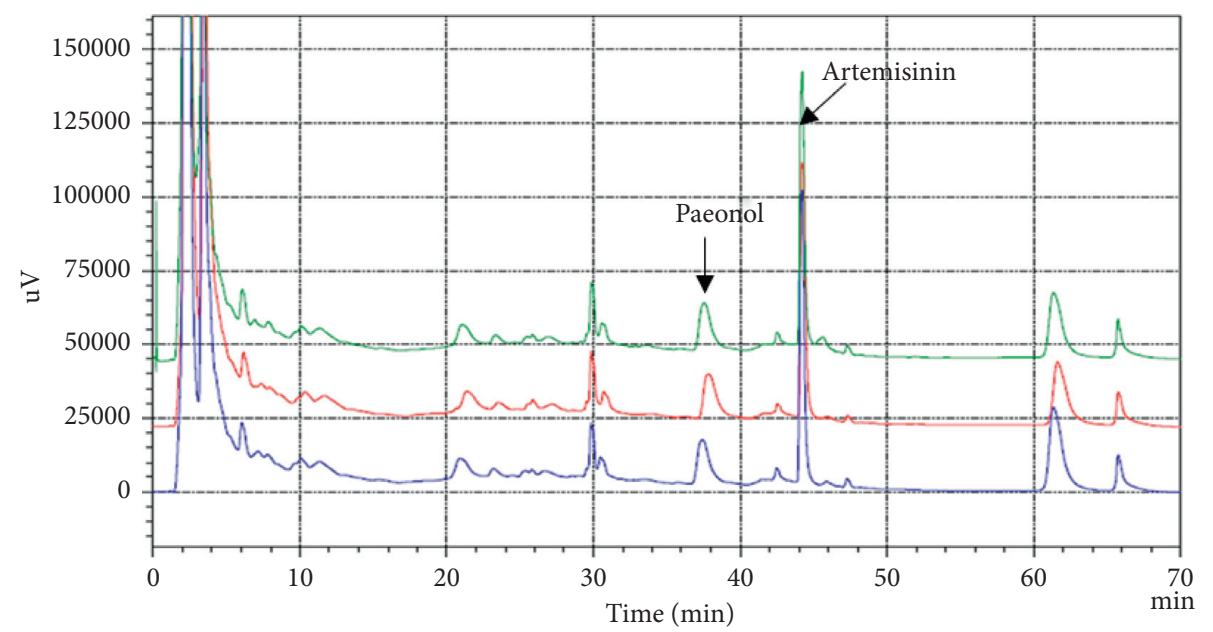

(c)

FiguRE 1: HPLC fingerprint chromatogram of THMGT. (a, b) Chromatogram of the two standard compounds, paeonol and artemisinin, respectively. (c) HPLC chromatograms of different THMGT decoctions have similar patterns.

THMGT-induced selective cytotoxicity, we examined the accumulation of DSB in THMGT-treated MCF-7 cells through the formation of $\gamma$-H2AX. Several studies have demonstrated that phosphorylation of histone $\mathrm{H} 2 \mathrm{AX}$, called $\gamma$-H2AX, is specific for DSB formation and not formed in other cellular DNA damage [37]. Compared with untreated cells, THMGT treatment at a concentration of $3 \mathrm{mg} / \mathrm{ml}$ increased $\mathrm{H} 2 \mathrm{AX}$ phosphorylation after $3 \mathrm{~h}$, as determined by immunofluorescence staining analysis. Furthermore,
THMGT did not induce DSB formation in human primary fibroblasts (Figures 3(a) and 3(b)). In addition, the result of MTT assay showed that the proliferation level of MCF-7 cells treated with THMGT was diminished to $60 \%$ in comparison with the nontreated cells after $9 \mathrm{~h}$, while the proliferation of the human primary fibroblasts was not affected (Figure 3(c)). These results indicate that THMGT selectively induces DSB lesions, thereby causing an antiproliferation in human breast cancer cells MCF-7. 


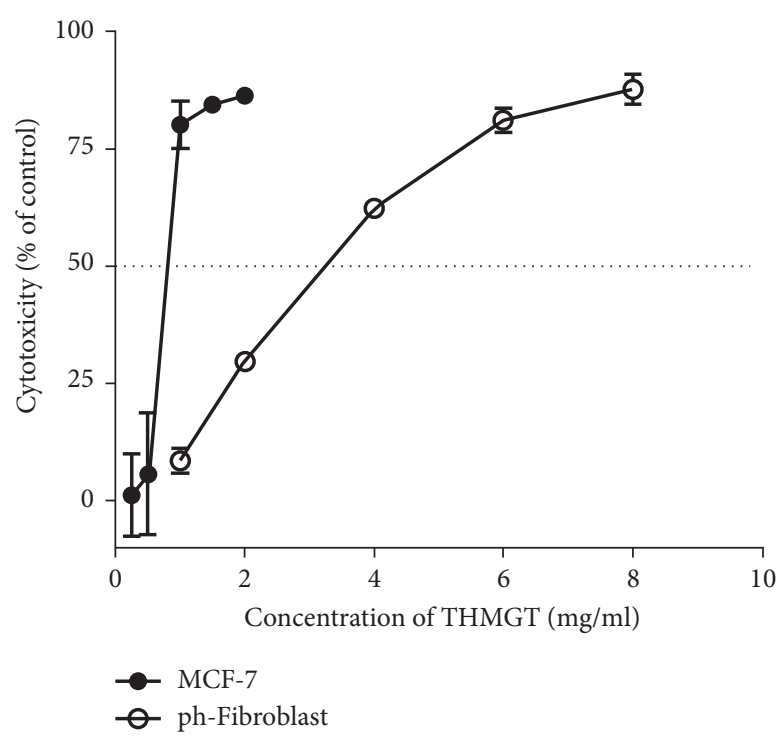

(a)

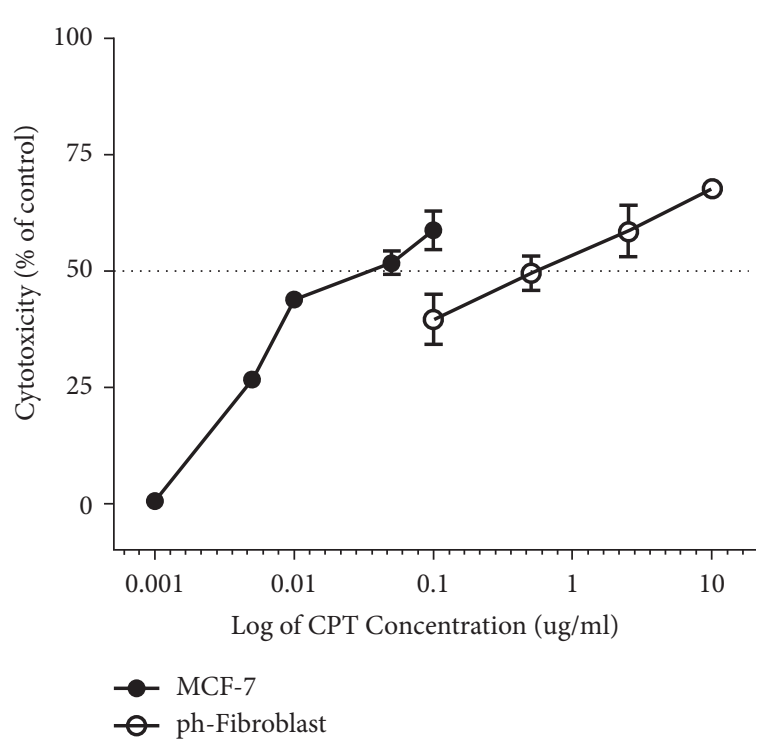

(b)

Figure 2: Cytotoxicity of THMGT on MCF-7 cells and primary human fibroblasts from healthy donor (ph-fibroblast). (a) MCF-7 cells and ph-fibroblasts were treated with THMGT at different concentrations for 48 h. Cytotoxicity was detected by the SRB assay. (b) MCF-7 cells and ph-fibroblasts were treated with CPT as a positive control at different concentrations for $48 \mathrm{~h}$. Cytotoxicity was detected by the SRB assay. Data are shown as mean $\pm \mathrm{SD}$ of three independent experiments.

3.4. THMGT Induced Cell Cycle Arrest at the S Phase in MCF-7 Cells. To understand whether THMGT inhibits the proliferation of MCF-7 cells through a cell cycle specific or nonspecific effect, flow cytometric analysis of cell cycle distribution based on DNA content was performed on PIstained MCF-7 cells exposed to THMGT at a concentration of $3 \mathrm{mg} / \mathrm{ml}$ for 3,6 , and $9 \mathrm{~h}$. Significant augmentation of the cell population in the $S$ phase of treated MCF-7 cells compared to nontreated cells was observed at 3 and $6 \mathrm{~h}$ treatment, indicating a S-phase arrest effect of THMGT on MCF-7 cells. After $9 \mathrm{~h}$ exposure to THMGT, half of the cell population was found in the sub-G1 area (Figure 4 and Table 1). These results suggest that the S-phase arrest observed at 3 and $6 \mathrm{~h}$ treatment with THMGT resulted in apoptosis induction in MCF-7 cells, an event evident at $9 \mathrm{~h}$ time point.

3.5. THMGT Induced Apoptosis in MCF-7 Cells. Apoptosis induction is a common mechanism of action of numerous anticancer compounds. To investigate the apoptosis induction capacity of THMGT, MCF-7 cells were stained with PI and Annexin V and subsequently analyzed by flow cytometry after treatment with or without THMGT at a concentration of $3 \mathrm{mg} / \mathrm{ml}$ for 3,6 , and $9 \mathrm{~h}$. Survival cells after treatment exhibited no staining; cells at early apoptosis stage were positive with Annexin V staining whereas late apoptotic cells were stained with both Annexin V and PI. Necrotic cells only displayed PI staining. As shown in Figure 5 and Table 2, compared to nontreated cells, the survival fraction of MCF-7 cells after 3, 6, and $9 \mathrm{~h}$ treatment with THMGT decreased progressively from $76 \%$ to $18 \%$ of total cells. The fraction of apoptotic cells increased with treatment time, with late apoptotic stage cells exhibiting a striking augmentation to reach $64 \%$ after $9 \mathrm{~h}$ treatment compared to $10 \%$ at $3 \mathrm{~h}$ treatment. These results clearly indicate an apoptosis induction effect of THMGT on MCF-7 cells, beginning before the $6 \mathrm{~h}$ time point.

3.6. THMGT Activated Checkpoint Kinase 1 (CHK1)-Mediated DNA Damage Response (DDR), While Inhibited the Expression of ATR Protein. To further reveal the mechanism of THMGT inducing DSBs, leading cell cycle arrest at the S phase and apoptosis in MCF-7 cells, we analyzed the expression levels of DNA damage signaling molecules, including $\gamma$-H2AX, ATR, CHK1, TP53, and MDM2, and the phosphorylation of CHK1 at S345 and TP53 at S15. Analyses of proteins that contributed to DNA damage response in MCF-7 cells exposed to $3 \mathrm{mg} / \mathrm{ml}$ THMGT showed that the levels of $\gamma$-H2AX, an indicator of DNA damage, were markedly increased compared to nontreated cells for all the three time points. The ATR expression was progressively reduced since the $3 \mathrm{~h}$ time point and was not observable at $9 \mathrm{~h}$ after treatment. We observed a marked increased signal for the S345 phosphorylated form of CHK1 (pCHK1) at the $3 \mathrm{~h}$ time point, followed by dramatic signal decreases at 6 and $9 \mathrm{~h}$ time points. The CHK1 expression in MCF-7-treated cells was increased compared to control cells at $3 \mathrm{~h}$ time point, and unchanged compared to control cells for two remain time points investigated. Both TP53 and its phosphorylated form at S15 (pTP53) also expressed a sharp upregulation in MCF-7 cells at $3 \mathrm{~h}$ time point followed by a progressive time-dependent downregulation. The expression of TP53 and especially TP53 phosphorylated at S15 in MCF-7 cells showed an important increase at $3 \mathrm{~h}$ time point 


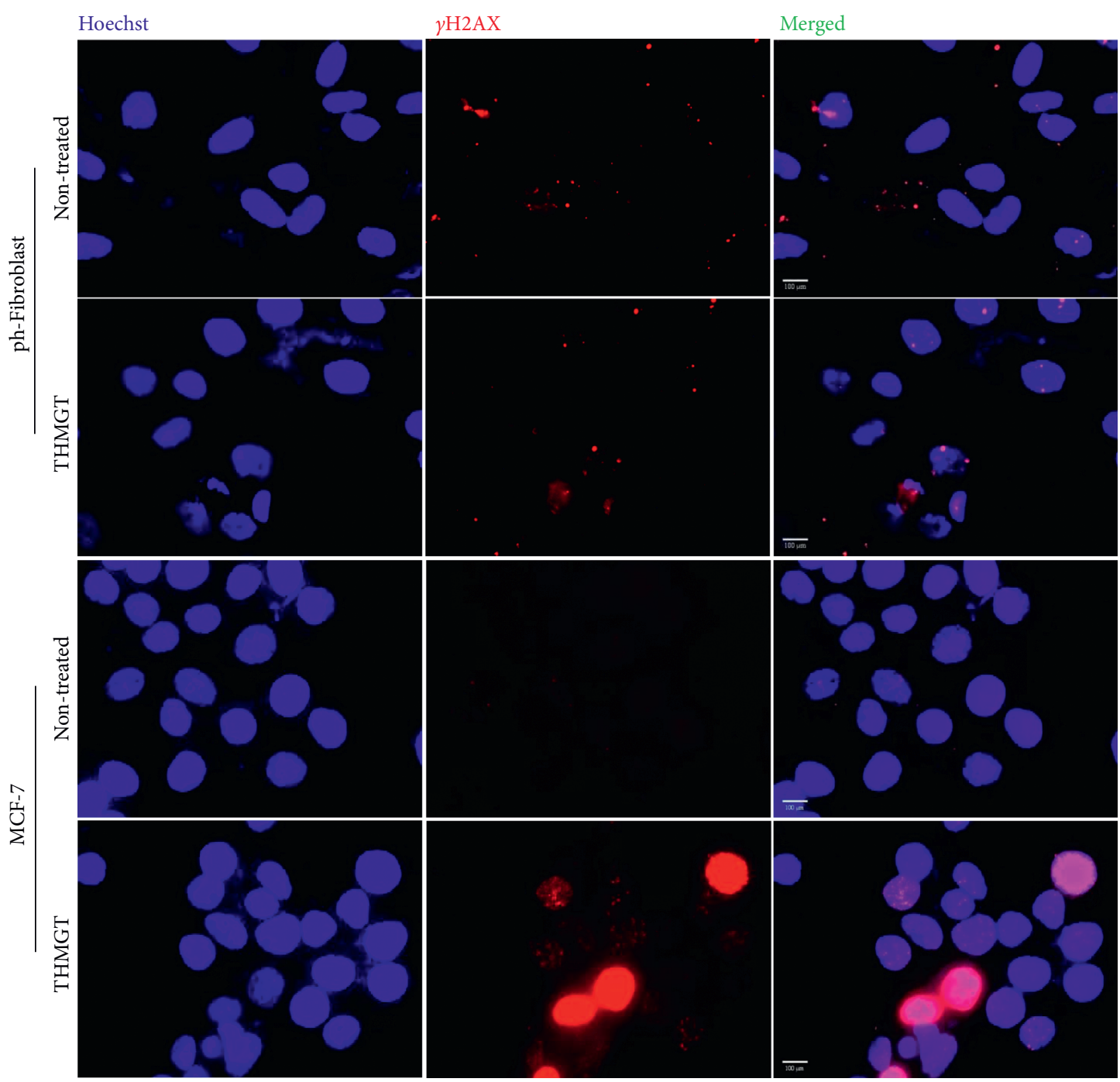

(a)
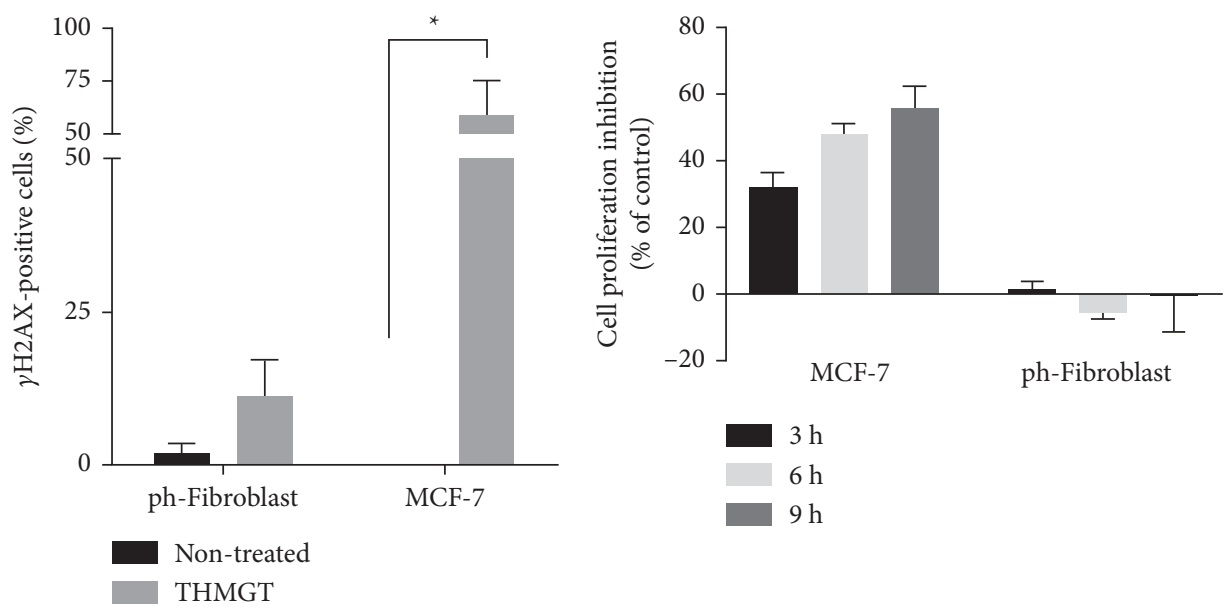

(b)

(c)

FIGURE 3: DSB accumulation in MCF-7 cells treated with THMGT. (a) Immunofluorescence staining of $\gamma$-H2AX foci in MCF-7 cells and phfibroblasts. Cells were treated with THMGT at a concentration of $3 \mathrm{mg} / \mathrm{ml}$ for $3 \mathrm{~h}$ and stained with a primary antibody against $\gamma$-H2AX and FITC-conjugated secondary antibody. Nuclei were counterstained with Hoechst. The data presented are representatives of three independent experiments. (b) Quantitation of the immunofluorescence staining data obtained from three independent experiments is shown $\left({ }^{*} p<0.05\right)$. (c) Antiproliferative effects of THMGT on MCF-7 cells and ph-fibroblast. Cells were treated with THMGT at a concentration of $3 \mathrm{mg} / \mathrm{ml}$ for 3,6 and $9 \mathrm{~h}$ and the proliferation was determined by the MTT assay. Data are shown as mean \pm SD from at least three independent experiments. 




FIGURE 4: THMGT induced cell cycle arrest at the S phase. MCF-7 cells were treated with THMGT at concentration of $3 \mathrm{mg} / \mathrm{ml}$ for 3, 6, and $9 \mathrm{~h}$ PI staining of the fixed cells was performed to obtain the flow cytometry-based cell cycle distribution profiles of the analyzed cells. The cell cycle phases are depicted in each panel.

TABLE 1: Cell cycle analysis of MCF-7 cells exposed to $3 \mathrm{mg} / \mathrm{ml}$ THMGT for 3, 6, and 9 hours.

\begin{tabular}{|c|c|c|c|c|c|c|}
\hline \multirow{3}{*}{ Phase } & \multicolumn{6}{|c|}{ Proportion of cell population (\%) determined at different time points } \\
\hline & \multicolumn{2}{|c|}{$3 \mathrm{~h}$} & \multicolumn{2}{|c|}{$6 \mathrm{~h}$} & \multicolumn{2}{|c|}{$9 \mathrm{~h}$} \\
\hline & Nontreated & THMGT & Nontreated & THMGT & Nontreated & THMGT \\
\hline sub-G1 & $1.0 \pm 0.1$ & $1.2 \pm 0.5$ & $0.6 \pm 0.6$ & $2.3 \pm 3.0$ & $1.5 \pm 1.0$ & $50.8 \pm 8.8^{* *}$ \\
\hline G1 & $38.7 \pm 3.4$ & $40.3 \pm 3.7$ & $47.9 \pm 6.1$ & $39.9 \pm 3.0$ & $45.1 \pm 4.9$ & $20.4 \pm 2.1^{* *}$ \\
\hline $\mathrm{S}$ & $17.3 \pm 0.6$ & $23.1 \pm 2.8^{* *}$ & $15.5 \pm 1.9$ & $19.4 \pm 0.6^{*}$ & $16.7 \pm 4.0$ & $11.5 \pm 4.3$ \\
\hline $\mathrm{G} 2 / \mathrm{M}$ & $33.7 \pm 3.2$ & $30.3 \pm 2.8$ & $27.4 \pm 5.4$ & $30.7 \pm 2.9$ & $29.6 \pm 4.1$ & $11.4 \pm 4.1^{* *}$ \\
\hline
\end{tabular}

Statistical analyses were performed using a two-tailed Student's $t$-test. ${ }^{* *} p<0.01 ;{ }^{*} p<0.05$. Data are shown as mean \pm SD of three independent experiments.

compared to control cells. This increased expression was maintained at $6 \mathrm{~h}$ time point though lower than that at $3 \mathrm{~h}$ time point. A decreased expression of MDM2, the negative regulator of $\mathrm{p} 53$, was observed for the three time points (Figure 6). These results suggest that THMGT induces DSB accumulation and consequently causes DDR through the ATR pathway in MCF-7 cells.

\section{Discussion}

TCM utilizes a holistic approach based on multicomponent drugs to address different targets in the body. In cancer treatment, herbal formulations based on combinations of ingredients are largely used. In Vietnam, THMGT is a formula used for supportive care in cancer treatment for patients who underwent chemotherapy or radiotherapy. So far, different ingredients from THMGT have been demonstrated to have anticancer activity $[7,8,14,23,31]$. To expand the clinical use and explore novel functions of THMGT, we evaluated the antiproliferative and apoptosisinduction effects of the formula on cancer cells, which have not been elucidated yet. Our results demonstrated that THMGT triggered DSB accumulation, ATR-CHK1-mediated S-phase arrest, and ultimately apoptotic death in human breast cancer cells MCF-7 with minimal effects on cultured primary fibroblasts from a healthy donor.

We observed that MCF-7 cells expressed a $\gamma$-H2AX accumulation in only $3 \mathrm{~h}$ after THMGT exposure denoted DSBs as the main DNA lesions. At the same time point, we observed a significant increase proportion of S-phase cells 




Figure 5: THMGT induced the apoptosis of MCF-7 cells. MCF-7 cells were treated with THMGT at a concentration of $3 \mathrm{mg} / \mathrm{ml}$ for 3, 6, and $9 \mathrm{~h}$ Annexin V/PI staining was performed to detect apoptosis. The lower right quadrant of the fluorescence activated cell sorting (FACS) output indicates the percentage of early apoptotic cells (Annexin V-stained cells), while the upper right quadrant indicates the percentage of late apoptotic cells (Annexin V+/PI-stained cells).

TABLE 2: THMGT induced the apoptosis of MCF-7 cells.

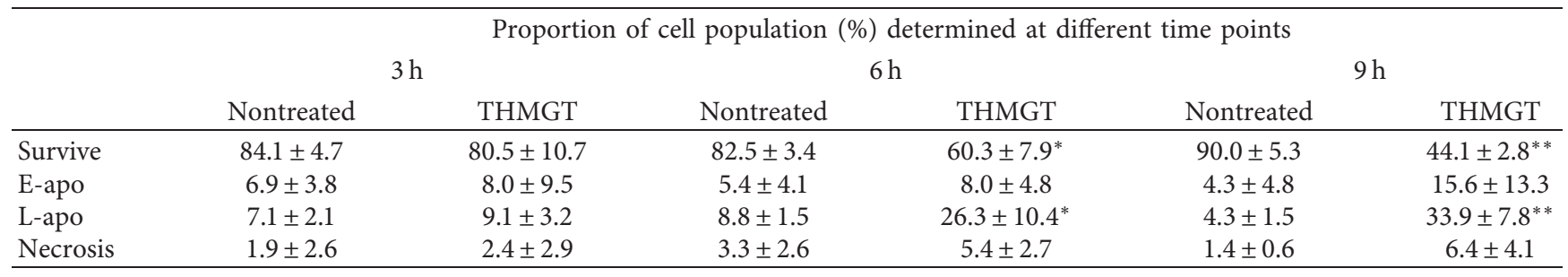

E, early; L, late; statistical analyses were performed using a two-tailed Student's $t$-test. ${ }^{* *} p<0.01 ;{ }^{*} p<0.05$. Data are shown as mean \pm SD of three independent experiments.

that indicated an S-phase arrest. The S-phase arrest could occur as an independent event from DDR or as the consequence of dramatic unresolved DNA damage.

Human cells respond to DNA damage by inducing checkpoint pathways to arrest cell cycle progression, giving opportunities for DNA repair machinery to proceed. The first step in the DDR consists of sensing the DNA lesions. The "sensors" of the checkpoints are ATM and ATR kinases that subsequently activate "effector" kinases CHK2 and CHK1, respectively. Depending on the type of lesion and cell cycle phase it occurs, different pathways are involved. It is proposed that the ATM-CHK2 pathway controls the G1 checkpoint and the ATR-CHK1 pathway controls the S and
G2/M checkpoints [38]. Furthermore, ATR monitors a replication fork progression and is responsible for maintaining replication fidelity. Checkpoint activation is triggered when replication forks are stalled by abnormally structured or damaged DNA [39]. In this study, THMGTtreated MCF-7 cells showed increased CHK1 phosphorylation at $\mathrm{S} 345$ at $3 \mathrm{~h}$ time point, followed by striking signal decreases at 6 and $9 \mathrm{~h}$ time points, while the protein expression was unchanged compared to control cells for the three time points investigated. The phosphorylated CHK1, which in turn induced phosphorylation of TP53 at S15 in the treated MCF-7 cells at 3-h time point that triggered an S checkpoint, and the consequent S-phase arrest under a DNA 


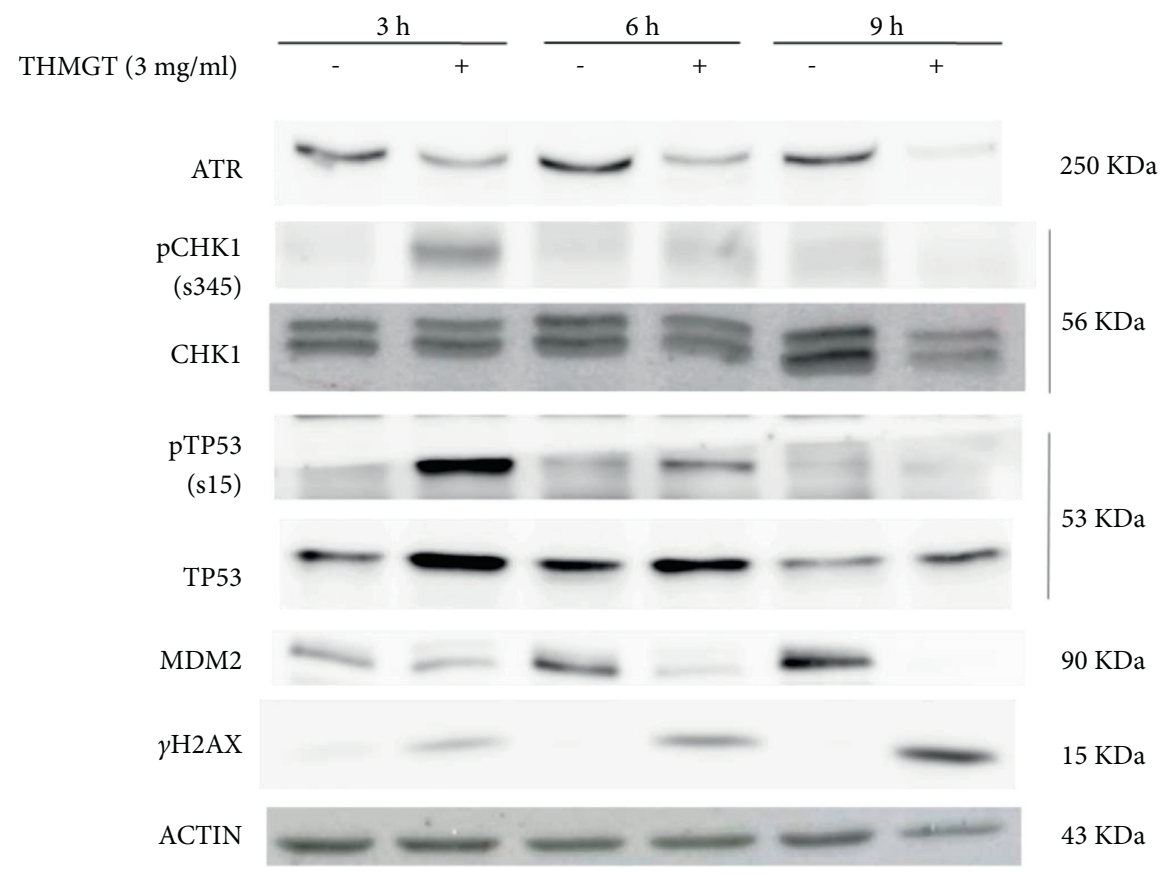

(a)

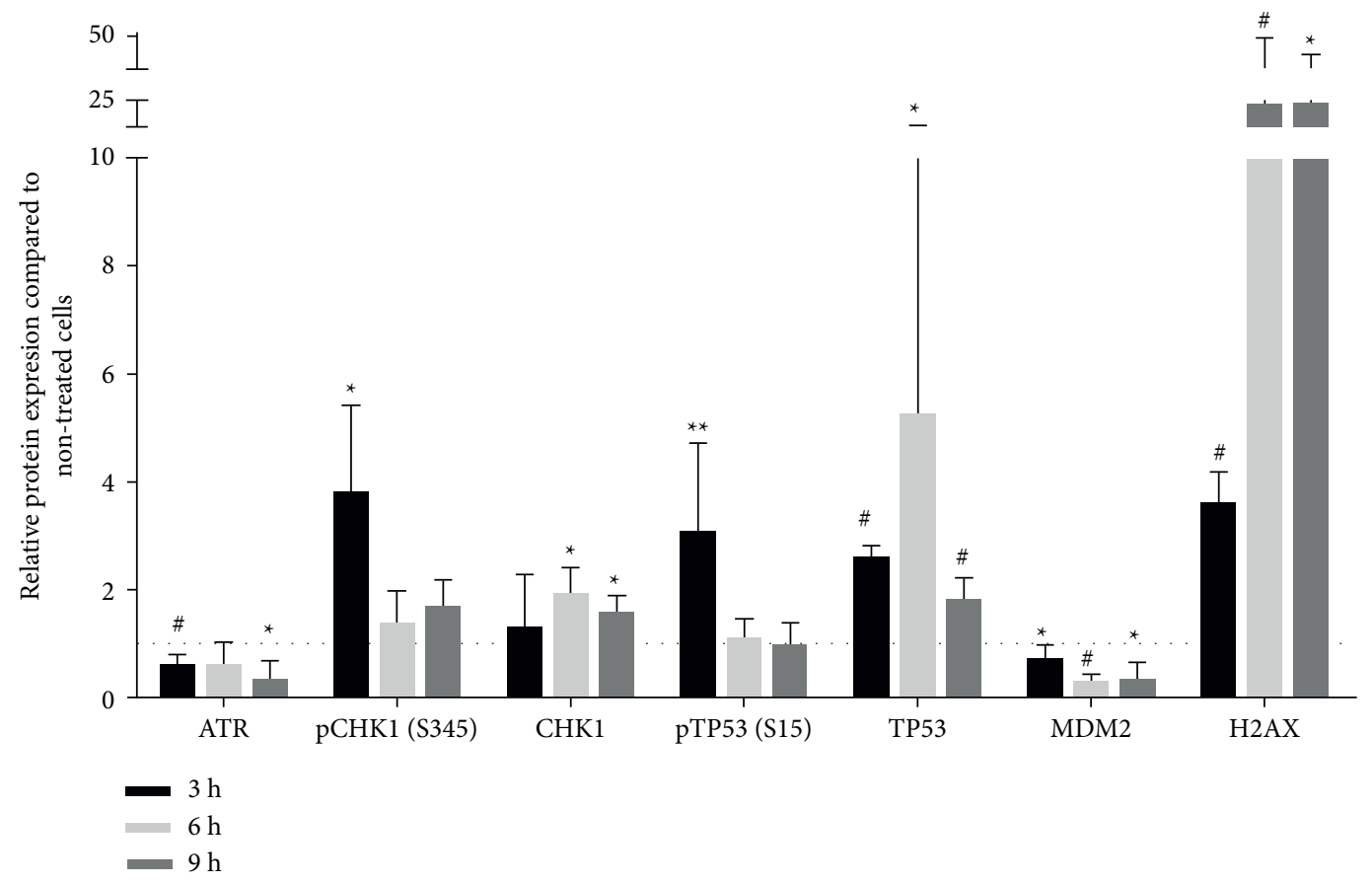

(b)

FIGURE 6: THMGT triggered DDR in MCF-7 cells. (a) The cells were treated with THMGT at a concentration of $3 \mathrm{mg} / \mathrm{ml}$ for 3,6 , and $9 \mathrm{~h}$ Collected cells were analyzed for the expressed levels of ATR, pCHK1, CHK1, pTP53, TP53, MDM2, and $\gamma$-H2AX by western blot. $\beta$-Actin expressions were measured as internal controls to show equal protein loading. The data presented are representatives of three independent experiments with similar results. (b) Relative protein level compared the nontreated cells at each time point $\left({ }^{*} p<0.05,{ }^{\#} p<0.1\right)$.

damage stimulus. Notably, we observed that the expression of ATR protein in MCF-7 cells was progressively reduced since $3 \mathrm{~h}$ time point and was not observable at $9 \mathrm{~h}$ after treatment with THMGT. CHK1 is rapidly phosphorylated at S317 and S345 by ATR in response to DNA damage. Therefore, the initial occurrence of phosphorylated CHK1 at
S345 observed in this study suggested an early induction of ATR-mediated DDR by THMGT. However, THMGT treatment decreased the expression of ATR in MCF-7 cells and thus caused the subsequent reduction in phosphorylated CHK1 abundance, implicating an attenuated DDR. Indeed, nine hours after THMGT exposure, histone $\mathrm{H} 2 \mathrm{AX}$ 
molecules remained highly phosphorylated in the MCF-7 cells compared with nontreated cells suggesting delayed DSB repair or accumulation of unrepaired DNA damage. It has been reported that, in the absence of either ATR or CHK1, mammalian cells rapidly lose viability, most likely because of a disruption in DNA replication fidelity, ultimately resulting in apoptotic death $[40,41]$. These might explain the early accumulation of S-phase MCF-7 cells followed by rapid apoptosis process observed in the above-mentioned flow cytometric analysis. Selective cytotoxicity toward cancer cells with minimal harm to normal cells is an ideal approach in cancer treatment. In normal cells, DNA lesions activate ATM-CHK2 and/or ATR-CHK1 pathways that mediate G1/S, S, and G2/M checkpoints to arrest cell cycle progression for DNA repair. Many cancers exhibit loss of G1/S checkpoints through TP53, ATM mutations, or Rb loss. This results in that the cancer cells rely on later checkpoints for DNA repair and cell survival, including the ATR-CHK1 pathway. If the ATR-CHK1 pathway is suppressed in G1/S checkpoint-deficient cells in the presence of DNA lesions, cells will not trigger cell cycle arrest for DNA repair, leading to cell death. Thus, inhibiting the ATR-CHK1 pathway has been an attractive strategy to selectively sensitize G1/S checkpoint-deficient cancer cells to therapies that damage DNA, without compromising normal cells with proficient the G1/S checkpoint [38]. Moreover, it is demonstrated that a slight reduction of functional ATR was sufficient to be lethal in oncogenic tumors while sparing normal bone marrow and intestinal cells [42]. Therefore, in this study, the translational downregulation of ATR, a couple with the induction of cellular DNA damage might contribute to selectively targeting MCF-7 cells as well as potentially other cancer cells by THMGT in future investigations.

THMGT includes five ingredients, Herba Artemisiae annuae, Carapax Trionycis, Rhizoma Anemarrhenae, Moutan Cortex, and Radix Rehmanniae. Previous studies have proven that artemisinin and timosaponin AIII, major active components of Artemisia annua and Anemarrhena asphodeloide, respectively, were capable of inducing DNA damage in cancer cell lines $[43,44]$. Particularly, artesunate, an artemisinin's derivative, provoked a DDR with phosphorylation of ATM, ATR, CHK1, and CHK2 in LN-229 glioma cells after 8-hour treatment [45], while timosaponin AIII activated DDR through the ATM-CHK2 pathway in MCF-7 cells after treatment for $10-20 \mathrm{~min}$ [44]. These compounds have been demonstrated arresting a cell cycle at either the G1 or G2/M phase, and subsequently triggering apoptosis in tumor cells $[44,46]$. Furthermore, according to the HPLC analysis, artemisinin and paeonol are the major components of THMGT. However, paeonol, an active ingredient in Moutan cortex, shows anti-inflammatory, antitumor, and antioxidant properties and inhibits migration and metastasis of cancer cells based on current report [12-16]. Therefore, the sustained DSB formation and S-phase arrest observed in THMGT-treated MCF-7 cells at least partially resulted from a combined effect of two ingredients: Artemisia annua and Anemarrhena asphodeloide. Interestingly, to the best of our knowledge, none of individual THMGT components has been shown to downregulate the expression of ATR leading to attenuated DDR. This emphasizes the use of a mixture of ingredients in traditional medicine preparation, resulting in increasing the effectiveness of herbal remedies due to synergistic effects. Future investigations will evaluate the relationship between the THMGT ingredients and the ATR-CHEK1 signaling pathway.

Although not essential for the repair of the majority of DSBs, the ATM activity is required for the repair of a subset of DSB generally associated with heterochromatin [38]. Previous studies have shown that the ATM gene was disrupted in the human breast cancer cell line MCF-7 [47]. Targeting DNA damage checkpoint kinase, such as ATR/ ATM, could be promising for cancer treatment. Therefore, it is necessary to conduct more in-depth studies to comprehensively understand whether THMGT has any effect on the DDR signaling pathway ATM-CHK2.

In conclusion, the traditional remedy THMGT expressed high selective cytotoxicity and antiproliferation on MCF-7 cells toward human primary fibroblasts from a healthy donor. The cytotoxicity and antiproliferation of THMGT relied on its capacity of simultaneous inducing DNA damage and DDR attenuation contributed to the S-phase arrest, and ultimate apoptosis. These results supported the potential utility of this formula as complementary healthcare for chemotherapy and radiotherapy. Further studies to clarify mechanisms underlying the selective antiproliferation and to predict the optimal timing of drug administration are needed.

\section{Data Availability}

The data used to support the findings of this study are included within the article and the supplementary information file.

\section{Conflicts of Interest}

The authors declare no conflicts of interest.

\section{Authors' Contributions}

HTNT performed experiments; HTNT, TVN, and TDHH interpreted the results and wrote the manuscript. All the authors discussed and approved the final version.

\section{Acknowledgments}

The authors thank Dr. Thi Hong Linh Ha (Traditional Medicine Hospital, HCMC, Vietnam) and Dr. Duc Nghia Nguyen (Tue Lan Traditional Medicine and Medical Clinic, HCMC, Vietnam) for providing us THMGT decoctions and its ingredients. This research was funded by Vietnam National University Ho Chi Minh City (VNU-HCM) under grant no. C2016-18-06.

\section{Supplementary Materials}

Table S1: antibodies used for western blot. (Supplementary Materials) 


\section{References}

[1] I. Hyodo, N. Amano, K. Eguchi et al., "Nationwide survey on complementary and alternative medicine in cancer patients in Japan," Journal of Clinical Oncology, vol. 23, no. 12, pp. 2645-2654, 2005.

[2] W. Xu, A. D. Towers, P. Li, and J.-P. Collet, "Traditional Chinese medicine in cancer care: perspectives and experiences of patients and professionals in China," European Journal of Cancer Care, vol. 15, no. 4, pp. 397-403, 2006.

[3] S. Adorisio, A. Fierabracci, A. Rossetto et al., "Integration of traditional and western medicine in Vietnamese populations: a review of health perceptions and therapies," Natural Product Communications, vol. 11, no. 9, Article ID 1934578X1601100, 2016.

[4] E. Hsu, "The history of qing hao in the Chinese materia medica," Transactions of the Royal Society of Tropical Medicine and Hygiene, vol. 100, no. 6, pp. 505-508, 2006.

[5] K. S. Kim, S. Lee, Y. S. Lee et al., "Anti-oxidant activities of the extracts from the herbs of Artemisia apiacea," Journal of Ethnopharmacology, vol. 85, no. 1, pp. 69-72, 2003.

[6] L. Anfosso, T. Efferth, A. Albini, and U. Pfeffer, "Microarray expression profiles of angiogenesis-related genes predict tumor cell response to artemisinins," The Pharmacogenomics Journal, vol. 6, no. 4, pp. 269-278, 2006.

[7] J. F. S. Ferreira, D. L. Luthria, T. Sasaki, and A. Heyerick, "Flavonoids from Artemisia annua L. as antioxidants and their potential synergism with artemisinin against malaria and cancer," Molecules, vol. 15, no. 5, pp. 3135-3170, 2010.

[8] D. Wang, Z. Wang, and C. Yu, "Endometriosis treated by the method of resolving blood stasis to eliminate obstruction in the lower-jiao," Journal of Traditional Chinese Medicine, vol. 18, no. 1, pp. 7-11, 1998.

[9] S.-G. Guo, W. Zhang, T. Jiang et al., "Influence of serum collected from rat perfused with compound Biejiaruangan drug on hepatic stellate cells," World Journal of Gastroenterology, vol. 10, no. 10, pp. 1487-1494, 2004.

[10] H. J. Lin, C. P. Tseng, C. F. Lin et al., "A Chinese herbal decoction, modified yi guan jian, induces apoptosis in hepatic stellate cells through an ROS-mediated mitochondrial/caspase pathway," Evidence-based Complementary and Alternative Medicine, vol. 2011, Article ID 459531, 8 pages, 2011.

[11] H. Xie and V. Preast, Xie's Chinese Veterinary Herbology, John Wiley \& Sons, Hoboken, NJ, USA, 2011.

[12] H. Matsuda, T. Ohta, A. Kawaguchi, and M. Yoshikawa, "Bioactive constituents of Chinese natural medicines. VI. Moutan cortex. (2): structures and radical scavenging effects of suffruticosides A, B, C, D, and E and galloyl-oxypaeoniflorin," Chemical and Pharmaceutical Bulletin, vol. 49, no. 1, pp. 69-72, 2001.

[13] M. Wu and Z. Gu, "Screening of bioactive compounds from moutan cortex and their anti-inflammatory activities in rat synoviocytes," Evidence-based Complementary and Alternative Medicine, vol. 6, no. 1, pp. 57-63, 2009.

[14] G. Xing, Z. Zhang, J. Liu, H. Hu, and N. Sugiura, "Antitumor effect of extracts from moutan cortex on DLD-1 human colon cancer cells in vitro," Molecular Medicine Reports, vol. 3, no. 1, pp. 57-61, 2010.

[15] Y. K. Koo, J. M. Kim, J. Y. Koo et al., "Platelet anti-aggregatory and blood anti-coagulant effects of compounds isolated from Paeonia lactiflora and Paeonia suffruticosa," Die Pharmazie, vol. 65, no. 8, pp. 624-628, 2010.

[16] S. C. Wang, S. W. Tang, S. H. Lam et al., "Aqueous extract of Paeonia suffruticosa inhibits migration and metastasis of renal cell carcinoma cells via suppressing VEGFR-3 pathway," Evidence-based Complementary and Alternative Medicine, vol. 2012, Article ID 409823, 9 pages, 2012.

[17] C. H. Lau, C. M. Chan, Y. W. Chan et al., "Pharmacological investigations of the anti-diabetic effect of Cortex Moutan and its active component paeonol," Phytomedicine, vol. 14, no. 11, pp. 778-784, 2007.

[18] D. T. Ha, T. N. Trung, T. T. Hien et al., "Selected compounds derived from Moutan Cortex stimulated glucose uptake and glycogen synthesis via AMPK activation in human HepG2 cells," Journal of Ethnopharmacology, vol. 131, no. 2, pp. 417-424, 2010.

[19] Y. H. Shon and K. S. Nam, "Protective effect of Moutan Cortex extract on acetaminophen-induced hepatotoxicity in mice," Journal of Ethnopharmacology, vol. 90, no. 2-3, pp. 415-419, 2004.

[20] Y.-Y. Sung, T. Yoon, J. Y. Jang, S.-J. Park, and H. K. Kim, "Topical application of Rehmannia glutinosa extract inhibits mite allergen-induced atopic dermatitis in NC/Nga mice," Journal of Ethnopharmacology, vol. 134, no. 1, pp. 37-44, 2011.

[21] P. S. Wu, S. J. Wu, Y. H. Tsai, Y. H. Lin, and J. C. Chao, "Hot water extracted Lycium barbarum and Rehmannia glutinosa inhibit liver inflammation and fibrosis in rats," American Journal of Chinese Medicine, vol. 39, no. 6, pp. 1173-1191, 2011.

[22] I. Chen, H. Chang, H. Yang, and G. Chen, "Evaluation of total antioxidant activity of several popular vegetables and Chinese herbs: a fast approach with $\mathrm{ABTS} / \mathrm{H}_{2} \mathrm{O}_{2} / \mathrm{HRP}$ system in microplates," Journal of Food and Drug Analysis, vol. 12, no. 1, pp. 29-33, 2004.

[23] G.-H. Baek, Y.-S. Jang, S.-I. Jeong et al., "Rehmannia glutinosa suppresses inflammatory responses elicited by advanced glycation end products," Inflammation, vol. 35, no. 4, pp. 1232-1241, 2012.

[24] R. Zhang, J. Zhou, Z. Jia, Y. Zhang, and G. Gu, "Hypoglycemic effect of Rehmannia glutinosa oligosaccharide in hyperglycemic and alloxan-induced diabetic rats and its mechanism," Journal of Ethnopharmacology, vol. 90, no. 1, pp. 39-43, 2004.

[25] N. K. Hoa, D. V. Phan, N. D. Thuan, and C.-G. Ostenson, "Screening of the hypoglycemic effect of eight Vietnamese herbal drugs," Methods and Findings in Experimental and Clinical Pharmacology, vol. 31, no. 3, pp. 165-169, 2009.

[26] J.-Y. Kim, J.-S. Shin, J. H. Ryu et al., “Anti-inflammatory effect of anemarsaponin B isolated from the rhizomes of Anemarrhena asphodeloides in LPS-induced RAW 264.7 macrophages is mediated by negative regulation of the nuclear factor- $\kappa \mathrm{B}$ and $\mathrm{p} 38$ pathways," Food and Chemical Toxicology, vol. 47, no. 7, pp. 1610-1617, 2009.

[27] H.-S. Yeum, Y.-C. Lee, S.-H. Kim, S.-S. Roh, J.-C. Lee, and Y.-B. Seo, "Fritillaria cirrhosa, Anemarrhena asphodeloides, Lee-Mo-Tang and cyclosporine a inhibit ovalbumin-induced eosinophil accumulation and Th2-mediated bronchial hyperresponsiveness in a murine model of asthma," Basic and Clinical Pharmacology and Toxicology, vol. 100, no. 3, pp. 205-213, 2007.

[28] B. Lee, H. T. Trinh, K. Jung, S.-J. Han, and D.-H. Kim, "Inhibitory effects of steroidal timosaponins isolated from the rhizomes ofAnemarrhena asphodeloides against passive cutaneous anaphylaxis reaction and pruritus," Immunopharmacology and Immunotoxicology, vol. 32, no. 3, pp. 357-363, 2010.

[29] L.-K. Sy, S.-C. Yan, C.-N. Lok, R. Y. K. Man, and C.-M. Che, "Timosaponin A-III induces autophagy preceding 
mitochondria-mediated apoptosis in HeLa cancer cells," Cancer Research, vol. 68, no. 24, pp. 10229-10237, 2008.

[30] M. Kang, I. Jung, J. Hur et al., "The analgesic and anti-inflammatory effect of WIN-34B, a new herbal formula for osteoarthritis composed of Lonicera japonica Thunb and Anemarrhena asphodeloides BUNGE in vivo," Journal of Ethnopharmacology, vol. 131, no. 2, pp. 485-496, 2010.

[31] Y.-J. Kang, H.-J. Chung, J.-W. Nam et al., "Cytotoxic and antineoplastic activity of timosaponin A-III for human colon cancer cells," Journal of Natural Products, vol. 74, no. 4, pp. 701-706, 2011.

[32] F. W. King, S. Fong, C. Griffin et al., "Timosaponin AIII is preferentially cytotoxic to tumor cells through inhibition of mTOR and induction of ER stress," PLoS One, vol. 4, no. 9, Article ID e7283, 2009.

[33] C.-N. Lok, L.-K. Sy, F. Liu, and C.-M. Che, "Activation of autophagy of aggregation-prone ubiquitinated proteins by timosaponin A-III," Journal of Biological Chemistry, vol. 286, no. 36, pp. 31684-31696, 2011.

[34] M. N. Nguyen and T. D. Ho-Huynh, "Selective cytotoxicity of a Vietnamese traditional formula, Nam Dia long, against MCF-7 cells by synergistic effects," BMC Complementary and Alternative Medicine, vol. 16, Article ID 220, 2016.

[35] J. van Meerloo, G. J. L. Kaspers, and J. Cloos, "Cell sensitivity assays: the MTT assay," Methods in Molecular Biology, vol. 731, pp. 237-245, 2011.

[36] N. S. Gavande, P. S. Vandervere-Carozza, H. D. Hinshaw et al., "DNA repair targeted therapy: the past or future of cancer treatment?" Pharmacology \& Therapeutics, vol. 160, pp. 65-83, 2016.

[37] A. Georgoulis, C. E. Vorgias, G. P. Chrousos, and E. P. Rogakou, "Genome instability and $\gamma \mathrm{H} 2 \mathrm{AX}$," International Journal of Molecular Sciences, vol. 18, no. 9, 2017.

[38] H. L. Smith, H. Southgate, D. A. Tweddle, and N. J. Curtin, "DNA damage checkpoint kinases in cancer," Expert Reviews in Molecular Medicine, vol. 22, 2020.

[39] R. T. Abraham, "Cell cycle checkpoint signaling through the ATM and ATR kinases," Genes \& Development, vol. 15, no. 17, pp. 2177-2196, 2001.

[40] H. Takai, K. Tominaga, N. Motoyama et al., "Aberrant cell cycle checkpoint function and early embryonic death in Chk1(-/-) mice," Genes \& Development, vol. 14, no. 12, pp. 1439-1447, 2000.

[41] E. J. Brown and D. Baltimore, "ATR disruption leads to chromosomal fragmentation and early embryonic lethality," Genes \& Development, vol. 14, no. 4, pp. 397-402, 2000.

[42] A. M. Weber and A. J. Ryan, "ATM and ATR as therapeutic targets in cancer," Pharmacology \& Therapeutics, vol. 149, pp. 124-138, 2015.

[43] I. Aquino, M. S. F. Tsuboy, J. C. Marcarini, M. S. Mantovani, F. F. Perazzo, and E. L. Maistro, "Genotoxic evaluation of the antimalarial drugs artemisinin and artesunate in human HepG2 cells and effects on CASP3 and SOD1 gene expressions," Genetics and Molecular Research, vol. 12, no. 3, pp. 2517-2527, 2013.

[44] M. Zhang, J. Qu, Z. Gao et al., “Timosaponin AIII induces G2/ $\mathrm{M}$ arrest and apoptosis in breast cancer by activating the ATM/Chk2 and p38 MAPK signaling pathways," Frontiers in Pharmacology, vol. 11, pp. 1-15, 2021.

[45] N. Berdelle, T. Nikolova, S. Quiros, T. Efferth, and B. Kaina, "Artesunate induces oxidative DNA damage, sustained DNA double-strand breaks, and the ATM/ATR damage response in cancer cells," Molecular Cancer Therapeutics, vol. 10, no. 12, pp. 2224-2233, 2011.
[46] T. Efferth, "From ancient herb to modern drug: Artemisia annua and artemisinin for cancer therapy," Seminars in Cancer Biology, vol. 46, pp. 65-83, 2017.

[47] Y. J. Lu, A. Condie, J. D. Bennett, M. J. Fry, M. R. Yuille, and J. Shipley, "Disruption of the ATM gene in breast cancer," Cancer Genetics and Cytogenetics, vol. 126, no. 2, pp. 97-101, 2001. 